$11-2003$

\title{
Developing Communities of Instructional Practice: Lessons From Cincinnati and Philadelphia
}

Jonathan A. Supovitz

University of Pennsylvania, JONS@GSE.UPENN.EDU

Jolley Bruce Christman

Follow this and additional works at: https://repository.upenn.edu/cpre_policybriefs

Part of the Curriculum and Instruction Commons, Educational Sociology Commons, Education Policy Commons, and the Teacher Education and Professional Development Commons

\section{Recommended Citation}

Supovitz, Jonathan A. and Christman, Jolley Bruce. (2003). Developing Communities of Instructional Practice: Lessons From Cincinnati and Philadelphia. CPRE Policy Briefs.

Retrieved from https://repository.upenn.edu/cpre_policybriefs/28

View on the CPRE website.

This paper is posted at ScholarlyCommons. https://repository.upenn.edu/cpre_policybriefs/28

For more information, please contact repository@pobox.upenn.edu. 


\title{
Developing Communities of Instructional Practice: Lessons From Cincinnati and Philadelphia
}

\begin{abstract}
Over the past several years, education reformers have increasingly invested in the development of communities within schools as a central strategy to improve teaching and student learning. These communities come in various guises, including small schools, small learning communities, and teacher teams. Two assumptions about how these communities will enhance the quality of instruction underlie the push for these more intimate learning environments. First, supporters believe that teachers will get to know their students better and therefore be more able to respond to students' learning needs. Second, advocates contend that small communities will encourage teachers to collaborate more in order to improve their instructional practices. Thus, the theory of action underlying the development of teacher communities is that the fostering of these kinds of teacher communities will instigate improvements in the quality of instruction, which will lead to enhanced student learning. This issue of CPRE Policy Briefs examines the merit of these assumptions and the conditions under which communities of teachers can improve their instructional practices and bring about enhanced student learning.

The lessons for policymakers contained in this Brief come from large-scale evaluations of two major district reform initiatives - one in Philadelphia, Pennsylvania and the other in Cincinnati, Ohio - that were designed to foster the development of instructionally focused communities. The research from these two very different settings indicates that only under certain conditions will teacher communities flourish into communiDeveloping Communities of Instructional Practice: Lessons from Cincinnati and Philadelphia By Jonathan A. Supovitz and Jolley Bruce Christman ties engaged in instructional improvement. The findings suggest that in order for an investment in communities to pay off in widespread improvement in student learning, particular kinds of teacher communities are needed: those that are focused on improving the instructional core of schooling and provided with the necessary strategies, structures, and supports. With more specific guidance that helps teachers to hone their instructional craft knowledge, policymakers can foster communities of instructional practice.
\end{abstract}

\section{Disciplines}

Curriculum and Instruction | Educational Sociology | Education Policy | Teacher Education and Professional Development

\section{Comments}

View on the CPRE website. 


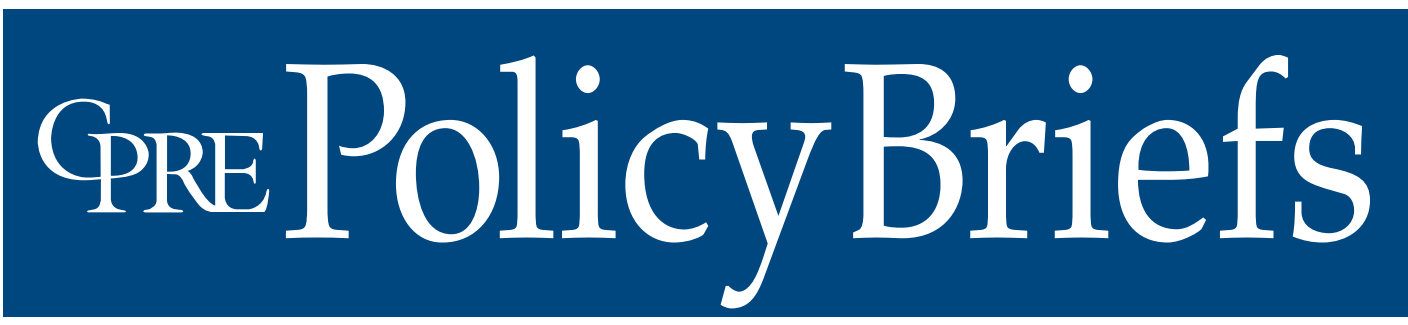

Reporting on Issues and Research in Education Policy and Finance

\title{
Developing Communities of Instructional Practice: Lessons from Cincinnati and Philadelphia
}

\author{
By Jonathan A. Supovitz and Jolley Bruce Christman
}

Over the past several years, education reformers have increasingly invested in the development of communities within schools as a central strategy to improve teaching and student learning. These communities come in various guises, including small schools, small learning communities, and teacher teams. Two assumptions about how these communities will enhance the quality of instruction underlie the push for these more intimate learning environments. First, supporters believe that teachers will get to know their students better and therefore be more able to respond to students' learning needs. Second, advocates contend that small communities will encourage teachers to collaborate more in order to improve their instructional practices. Thus, the theory of action underlying the development of teacher communities is that the fostering of these kinds of teacher communities will instigate improvements in the quality of instruction, which will lead to enhanced student learning. This issue of CPRE Policy Briefs examines the merit of these assumptions and the conditions under which communities of teachers can improve their instructional practices and bring about enhanced student learning.

The lessons for policymakers contained in this Brief come from large-scale evaluations of two major district reform initiatives - one in Philadelphia, Pennsylvania and the other in Cincinnati, Ohio - that were designed to foster the development of instructionally focused communities. The research from these two very different settings indicates that only under certain conditions will teacher communities flourish into communi- ties engaged in instructional improvement. The findings suggest that in order for an investment in communities to pay off in widespread improvement in student learning, particular kinds of teacher communities are needed: those that are focused on improving the instructional core of schooling and provided with the necessary strategies, structures, and supports. With more specific guidance that helps teachers to hone their instructional craft knowledge, policymakers can foster communities of instructional practice.

\section{Tale of Two Initiatives}

The structures of the reforms put in place in Philadelphia and Cincinnati were different in scope, but their purposes were remarkably similar. The communities in Cincinnati were small. Cincinnati's team-based schools were comprised of teacher teams of three-to-five teachers, who were intended to work with groups of between 60-120 students over multiple years. Small learning communities in Philadelphia, essentially schools within schools, were larger, comprising between 200-400 students and their teachers, who were also intended to stay with students over several years. In both cases, the reform architects theorized that teachers working together would benefit from the collective knowledge of their peers and that teachers working with students over multiple years would develop deeper relationships with both the students and their parents, thus becoming better equipped to meet the learning needs of the students. What follows is a more detailed description of each city's initiative and the reform context within which it unfolded.
November 2003

RB-39

Graduate School of Education

University of

Pennsylvania

\section{Consortium for Policy Research in Education \\ University of Pennsylvania}

Harvard University

Stanford University

University of Michigan

University of Wisconsin-Madison 


\section{Policy Briefs}

The theoretical rationale underlying the grouping of teachers into organizational units as a means of improving their instructional practices brings together research from a variety of disciplines, including organizational theory, management theory, social learning theory, and education theory. Organizational theorists (Galbraith, 1994; Mohrman, Cohen, \& Mohrman, 1995) argue that team-based work organizations can more effectively meet the challenges of knowledge-based work. The group practices that underlie learning organizations are seen as a means of creating a culture of continuous improvement (Deming, 1986; Senge, 1990). In order to improve their job skills, adults should learn both with and from each other (Wenger, 1998). Within education, a key rationale for teacher community is that it provides a more collegial work environment and a setting more conducive to teacher learning and growth (Darling-Hammond \& Sykes, 1999; McLaughlin \& Talbert, 2001; Resnick \& Hall, 1998). Christman, Cohen, and MacPherson (1997) view inquiry as central to the work of small communities. The small schools movement (Fine \& Somerville, 1998) emphasizes the benefits of more intimate environments for both teachers and students.

\section{Team-based Schooling in Cincinnati}

The Cincinnati Public Schools (CPS) is a medium-sized urban district with 79 schools and just under 50,000 students. Approximately $70 \%$ of the district's students are African American and 25\% are White. Just over $60 \%$ of the students receive free or reduced-price lunch. In the 1996-1997 school year, CPS undertook an ambitious comprehensive reform plan called Students First. The reform was designed to be a top-to-bottom restructuring effort focused on raising academic achievement, improving school safety, and reducing the dropout rate for all the district's students. According to then-superintendent J. Michael Brandt, "We're not a Cadillac that just needs a little fine-tuning. If we only tweaked around the edges we'd be sitting here five years from now and the results would be even worse" (Hendrie, 1996). As its primary instructional change policy, CPS adopted team-based schooling, a school reor-
The Consortium for Policy Research in Education (CPRE) is funded by the Institute of Education Sciences, United States Department of Education under Grant No. R308A960003. Opinions expressed in this Brief are those of the authors and do not necessarily reflect the views of the Institute of Education Sciences; the United States Department of Education; Research for Action; CPRE; or its institutional members.

ganization strategy in which teams of academic teachers take responsibility for developing appropriate instructional strategies to help their students, whom they teach over multiple years, to reach the state standards. The teams were to focus on the district's academic and behavioral standards, collaborate amongst themselves, work with parents/ caregivers, and were to be held mutually accountable for their students' learning over time.

Team-based schooling was adopted and the basic elements of its design were defined in CPS's 1997 collective bargaining agreement with the Cincinnati Federation of Teachers. The codified guidelines for the reform included five key elements. First, teams, organized by the gateway grades (K-3, $4-6,7-8,9-10)$, were to be composed of threeto-five core subject academic teachers who were to stay with a group of students for at least two years. Second, teams were to develop a curriculum and select instructional methods and materials consistent with their school's program focus and also had power to decide how to schedule and group their students. Third, teams were to take responsibility for all students they served and work to ensure that they met the district and school learning objectives. Fourth, teams controlled funding for instructional supplies, materials, and personnel. Finally, teams were to stay together for several years in order to ensure maximum benefits from collaboration and longer-term relations with students. Schools needed to adopt team-based schooling voluntarily and, by 1998, over half of the schools in the district were team-based.

\section{Small Learning Communities in Philadelphia}

The seventh largest district in the United States, the School District of Philadelphia serves 215,000 students in 257 schools. Most students live in poverty and cope with the 
stress and problems associated with economic disadvantage; $80 \%$ receive free or reducedprice lunch. In Philadelphia, all schools were asked to implement small learning communities, composed of 200-400 students whose teachers are responsible for their education over several years. Schools have between two and eight small learning communities, depending on their size. Small learning communities were an important component of Philadelphia's ambitious systemic reform effort, Children Achieving, which was launched in 1995 under then-Superintendent David Hornbeck. The Children Achieving reform sought to improve schools by decentralizing decision-making to the school and small learning community levels, while at the same time holding schools accountable for student learning. Central administrators set targets for schools and monitored students' progress on indicators including standardized test performance, attendance, and promotion and graduation rates. Content standards were developed to guide teachers' classroom instruction by identifying what students should know and be able to do.

Within this overall reform framework, small learning communities were intended to improve the conditions of teaching and learning, to strengthen relations between teachers and students, and to be the primary vehicle for improving instruction. To achieve these ends, central administrators provided schools with guidelines for how to organize small learning communities. A small learning community coordinator would provide instructional leadership to teachers and mentor and discipline students. Teachers would have a designated time during the school day to plan curriculum, share ideas, and discuss students. Teachers would link their classroom instruction to the small learning community's unifying theme and a community partner (e.g., a local business, community agency) would help teachers and students make real-world connections to in-school learning. Initially, district leaders did not provide strong guidance about curriculum or instructional practices; these decisions were left to teachers in their small learning communities. Later, in the refinement of the reform, a district-wide literacy initiative in the primary grades focused the instructional work of elementary schools and their small learning communities. There were not equivalent instructional strategies adopted in the middle and high schools.

It should be noted that teacher collaboration or communities within schools was not a radically new phenomenon in either district. In Cincinnati, the practice of teachers working closely with colleagues to plan and implement instruction was common practice even in the non-team-based elementary and middle schools. A survey conducted in 1998 indicated that $79 \%$ of elementary school teachers, $73 \%$ of middle school teachers, and $45 \%$ of high school teachers reported that they teamed with at least one other teacher. In Philadelphia, small learning communities had been the centerpiece of a previous high school restructuring effort. High school restructuring leaders believed that smaller, more intimate environments for teaching and learning would re-engage an aging teaching force in its profession and provide a more personalized, coherent, and rigorous educational experience for adolescents. During the mid-1980s, both Cincinnati and Philadelphia joined the national movement to create middle schools that would cater to the distinct developmental concerns of 11- to 14-yearolds. The majority of these middle schools contained smaller units, called houses. Yet, the new reforms put a more formal emphasis on communities as a mechanism for improving teaching and learning and provided better support for these efforts.

As mentioned earlier, embedded deep within the learning community reforms in both Cincinnati and Philadelphia were a set of assumptions about how these reforms would improve instruction and student learning. Reform leaders in both cities believed that small communities operating within larger schools would offer more personalized environments for teachers and students. Within these communities, leaders thought, teachers would more likely collaborate when they had frequent and close contact around a shared group of students. Teachers also would be more likely to design instructional strategies appropriate to their students when they came to know these stu- 
dents well over several years. For their part, students would more likely put forth greater effort when they felt well known by their teachers. Learning communities would unleash teachers' professional knowledge, the reasoning went, and renew teachers' commitment both to their profession and their students, and increase student engagement in learning. Reform leaders in both cities recognized that the new learning communities would need supports to take root and grow, but they believed that the new structures could flourish within existing school and district organizational arrangements. As we shall see, how these reforms unfolded and what their impacts were shed light on the shaky validity of many of these assumptions.

\section{Summary of Findings}

Despite the different reforms and the different contexts within which they operated, the evaluation findings about the two reforms were remarkably consistent. In both locales, the reforms positively influenced the communal culture of schools and the relationships among teachers. However, only in a subset of the schools, and teacher communities within, did the reforms penetrate the instructional culture between teachers around teaching and learning. In these cases, the communal reforms were coupled with an instructional intervention. Thus, in both cities, only where communities focused on changing the instructional practices of their members was there measurable improvements in student learning.

\section{Influence on School Culture}

Research in both sites indicated that the reforms had significant and positive influences on the environments within which schooling took place and teachers' efficacy within those environments. In Philadelphia, teacher survey data showed that teachers felt their schools to be safer and more orderly. Philadelphia teachers from all school levels reported that small learning communities made their schools more orderly because students spent less time in hallways traveling to classrooms (each small learning community had a designated area in the building), small learning community coordinators monitored student behavior and followed up with par- ents, and students themselves felt more connected to their small learning communities and wanted "to show respect." Philadelphia teachers also reported that small learning communities provided them with many more opportunities to interact with their colleagues than they had previously and teachers expressed appreciation for this increased collaboration. In Cincinnati, teachers in teambased schools felt more involved in a variety of school-related decisions than did their peers in the non-team-based schools. In both sites, the reforms also strengthened the professional community amongst teachers. Teachers in Cincinnati's team-based schools reported higher levels of interaction and collaboration with their peers than did teachers in the non-team-based schools.

The reforms were extremely popular with teachers in both Philadelphia and Cincinnati exactly because the reforms improved the working environment. School faculty in both sites were strong proponents of the community development aspect of their district's reform efforts. On a 1999 district-wide survey in Philadelphia, for example, more than $80 \%$ of responding teachers reported that they believed that small learning communities were beneficial for their school. In a 1998 survey of Cincinnati teachers in team-based schools, $85 \%$ said that team-based schooling had a positive effect on their school environment.

\section{Influence on Instructional Practice}

Changes in instructional practice associated with the formation of learning communities was uneven in both cities. In neither locale did the improvements in the culture of the school communities in and of itself translate into widespread and greater instructional focus. In Philadelphia, for example, each small learning community had a unifying theme that was intended to help students make connections across subject areas and between school and the "real world." In theory, the theme provided a focus for small learning community teachers to plan and teach engaging and intellectually challenging units of study together. In reality, however, themes most often took the superficial form of isolated events such as field trips and special assemblies. These efforts certainly contributed to building a shared identity in a 
small learning community. However, they did not promote the kind of professional collaboration around instruction in which teachers collectively investigated how to structure a rigorous investigation of a thematic topic that was connected to the district's content standards or how to help students develop their understanding of interdisciplinary concepts. Most of the thematic curricula observed by CPRE researchers was unchallenging and did not engage students in deep thinking.

In Cincinnati, an annual survey was used to track the changes and growth in instructional practice. On annual surveys from 1998 to 2001, teachers were asked about the frequency of their group instructional practices, like planning instructional strategies together, examining student work together, and communicating with other teachers about individual students in order to make instructional adjustments. Researchers identified three key dimensions of group instructional practice: academic preparation strategies, collective teaching practices, and student grouping strategies. None of these three group instructional practices was significantly different for teachers in the team-based schools than for teachers in the non-teambased schools. Further, these levels of group practice were generally static from year to year, suggesting that teams were not substantially deepening their practice over time. In all, only about a quarter of the teams within the team-based schools across the district were frequently practicing these three dimensions of group practice.

Qualitative observations of both small learning community meetings in Philadelphia and team meetings in Cincinnati schools shed light on why the reforms failed to increase instructional focus. Communities spent little time in discussions about teaching practices or in planning curricula. When instructional topics did arise, interaction took the form of one-way transmissions of information from one teacher to another. As a Cincinnati elementary school team member said, "Team issues are administrative, not academic. It has nothing to do with planning instruction. [There is] all this paperwork coming down from the district and school level." In few cases did communities move to more sophisticated levels of group instructional practice such as collective analysis of teaching or review of student work.

\section{Influence on Student Performance}

In both Philadelphia and Cincinnati, there was evidence to suggest that those communities that did engage in structured, sustained, and supported instructional discussions and that investigated the relationships between instructional practices and student work produced significant gains in student learning. In Philadelphia, there were test score gains in elementary schools throughout the district from 1996-2000, the time of Children Achieving. These gains are generally attributed to the district's literacy initiative in the primary grades. ${ }^{1}$ The literacy initiative provided a meaningful content element for the work of small learning community teachers in elementary schools that was absent in the secondary grades. The literacy initiative called for devoting a large block of morning time to language arts and the implementation of learning centers where students worked on assignments on their own while their classmates received intensive, customized assistance from their teacher. The literacy initiative provided training to teachers within their small learning community structures about particular instructional strategies such as guided reading, word study, modeled writing, and shared writing with independent literacy activities. Small learning communities offered a supportive environment for teachers to learn about the new materials and practices associated with the district's literacy initiative. At the same time, the literacy initiative gave teachers in the small learning communities a shared focus and purpose that in turn strengthened their professional community.

In Cincinnati, the overall test score gains of students in the team-based schools were indistinguishable from those of students in the non-team-based schools. Yet, multiple investigations found a relationship between group instructional practice and gains in stu-

\footnotetext{
${ }^{1}$ Full-day kindergarten and the district's accountability policies, which focused the system on improving test performance, were also major factors contributing to rising student achievement.
} 
dent learning. Several statistical analyses showed that teams that were engaged in instructional improvement programs like the Education Trust's Standards in Practice (SIP) program outperformed those teams that were not. The SIP model is designed to assist teachers to align classroom work with state and district standards and involves a six-step process based on analysis of an assignment and student work and development of a scoring guide.

CPRE's analyses of the performance of students on teams with different levels of implementation of group instructional practices indicated that the students on teams with higher use of group instructional practices learned more than did students on teams with lower levels of group instructional practices, after controlling for the background characteristics of students. A separate evaluation conducted by Cincinnati's department of research and evaluation (Holtzapple, 2001) showed that students of teams using SIP outperformed students of teams not using SIP, students of teachers using SIP alone, and students of teachers that were neither teaming nor using SIP. Thus, the evidence suggests that well-implemented communities provided important and necessary conditions for teachers to engage in the types of instructional practices that improve student learning, but they were not commonly the catalyst for teachers to engage in instructional improvement on their own.

\section{How School and District Leaders Can Support Teachers in their Efforts to Develop Communities of Instructional Practice}

School and district leaders who seek to foster communities of instructional practice can learn many things from the experiences of Cincinnati and Philadelphia that will increase the likelihood that the communities they develop in their schools are focused on instructional improvement. First, school and district leaders can increase the instructional focus of school communities by facilitating their engagement around instructional improvement and supporting them by creating professional learning opportunities for community members. Second, school and district leaders can provide organizational support for communities by providing time for community meetings and by rethinking the role of the central office and school administration in order to support the smaller communities within schools. Third, it is important that school and district leaders provide legitimacy to communities within schools so that the lines of authority are coherent and sanctioned. Finally, there are ways in which school and district leaders can organize communities to capitalize on the value of these structures. In this section, we expand on the ways that school and district leaders can support communities within schools to develop into communities of instructional practice.

\section{Focusing Communities Around Instruction}

Focus communities on the task of instructional improvement. There are myriad distractions that detour communities from grappling with instructional improvement. School and district leaders must realize that the creation of communities that engage in systematic inquiries about their instruction and how it relates to student learning is as much a cultural shift as it is an organizational one. While organizational structures can facilitate this change, they are just the means to facilitate the work of communities of instructional practice. School and district leaders can do several things to focus communities on instructionally related activities. First, school and district leaders can provide communities with the tools and training to develop structured routines in which they systematically inquire into the relationships between their practices and the learning of their students. Second, school and district leaders can organize data in the system so that it provides communities with meaningful information to guide their investigations. Third, they can establish processes for communities to be reviewed and provided with feedback about their instructional programs and their students' progress. Fourth, they can send a clear message throughout the system that improving instruction is the first priority of communities. Finally, they can facilitate the work of communities by helping with the logistical arrangements necessary for team teaching and cross-visitation. 
Create ongoing professional learning opportunities for community members. Communities of instructional practice represent a new way for teachers to work collaboratively, and both district and school leaders can play important roles in helping to connect communities of teachers to professional development experiences and technical assistance that capitalize on these new work arrangements. Teacher teams need professional development that takes advantage of their communal arrangements: learning opportunities that are connected to their content areas and to the materials they will be using in their classrooms that also capitalize on the social arrangements inherent in communities of practice. Teachers need opportunities to reflect on and analyze their teaching. As members of a community of practitioners, they also need to learn how to work together. They need strategies and tools that will help them plan, assess, and revise their efforts. District and school leaders must broker opportunities for professional development that are customized to the needs of particular communities. They can also play an important role in networking communities so that teachers can learn from the experiences of colleagues in other settings.

\section{Supporting Instructional Communities}

Provide time for community meetings that are focused on instructional conversations. Teacher communities need blocks of protected time together in order to engage in conversations about standards for student performance and how their instruction produces the student learning that they find represented in their students' work. Too often, team meetings in Cincinnati and Philadelphia became procedural, dominated by memos and requests from school and district administrators so that teams never got to the instructional conversations that were their purpose. Not only do communities need protected time that frees them to investigate instruction together, they also need structures to capitalize on the opportunities created by time together in order to have disciplined conversations about the connections between their instructional strategies and student learning. In Cincinnati, the SIP model and its practical examinations of teacher assignments and the resulting student work acted as just such a catalyst, providing team members with work around which to engage in conversations about ways in which their lessons were aligned with standards and the kinds of student work it produced.

Rethink the role of the central office and school administration and reshape their functions to support the smaller communities within schools. The creation of communities within schools requires changes in the behaviors of those both working inside and outside the communities. Central administrators, principals, and other school staff members need to rethink their responsibilities and the way they operate, and learn new skills. For example, the central office should report data by community as well as by individual student and school, those in charge of scheduling may need entirely new approaches to building rosters to accommodate communities, and principals will need to be very clear about what their authority will be in the new organizational structures. District-sponsored professional development should also capitalize on the synergy of teacher communities.

\section{Legitimizing Instructional Communities}

Codify the authority of community leaders and help them learn the skills necessary for instructional leadership. Schools are essentially flat organizations where teachers are considered peers and no one teacher has the authority to dictate to others how and what to teach. However, when developing communities, someone must have the legitimate authority to lead that community, developing consensus about the actions of the team and requiring others to participate and carry out team decisions. Community leaders need training on how to lead their communities. They especially need to learn how to lead their colleagues in developing and using a shared repertoire of community practices that will focus on what students are and are not learning and what can be done to improve their performance. Further, the limitations of authority vis-à-vis the school's principal must be clearly delineated. 
Even while providing guidance about instructional priorities, allow communities as much autonomy as possible over curriculum, staffing, scheduling, and budgets and be clear about the parameters of autonomy. Teachers invest in their communities when they have authority to make decisions. Autonomy enhances community identity and distinctiveness as teachers work together to decide what matters to their community and what they will emphasize in their work with one another and their shared students. When autonomy is promised but undermined by central office edicts and policy mandates, teachers become cynical about the possibility of meaningful community.

Provide communities with discretionary funds. Communities need resources. Even when teachers are using district and school curricula, they need some materials that reflect and support their community's customized instructional focus and approach. They also need resources to fund community events that help to build group identity and investment. It is important for teachers to have opportunities to make collective budgetary decisions. As they do so, they learn more about how to work together toward common goals and they sharpen the intentions and focus of the community.

\section{Organizing Instructional Communities}

Develop a system for community formation and membership that balances teacher choice with ensuring an equitable distribution of teacher experience and knowledge and diversity. A difficult, but crucial, decision that district and school leaders face is how communities within schools will be formed. Distributing instructional talent across sub-communities within a school allows for a more equitable allocation of teachers and ensures that students do not receive unequal learning opportunities over time. However, allowing teachers to selfdetermine their communities encourages ownership and engagement.

Develop communities that are both horizontal and vertical. Teacher teams ought to have vertical and horizontal attributes. Vertical relationships (i.e., teachers in grades K-2,
3-5, 6-8, 9-12) allow teachers to articulate across grades and even to loop with their students over multiple years. However, urban areas with high student mobility should not overestimate the benefits of looping. Horizontal relationships (teachers at the same grade level) allow teachers to talk with their peers who are teaching similar curriculum topics to students of the same age.

\section{Conclusion}

Communities of instructional practice are a powerful way for groups of teachers to engage in instructional improvement through sustained inquiry into their practice and investigations into ways that their teaching can most effectively produce greater student learning. Communities focused on instruction bring teachers out of isolated classrooms and engage them in structured ways to systematically explore together the relationships between their teaching and the learning of their students. Working together, teachers learn with and from each other, capitalizing on the ways that adults learn most effectively.

Yet, organizational restructuring that fosters social groupings of teachers without providing them with strategies and supports to engage in instructional improvement will likely produce communities, but these communities are unlikely to emerge as communities of instructional practice. Communities of instructional practice are specific types of communities that are focused on a particular goal: improving the learning of students through a structured investigation into teaching and its connection to the learning of students.

To support these particular kinds of communities, school and district leaders must provide communities with specific structures, strategies, and supports. Structures that facilitate community engagement in instructional practice include sufficient and protected time to meet and organization in such ways that capitalize on both the horizontal and vertical nature of schooling. Strategies include both ways for communities to constructively interact together and content-specific techniques for exploring stu- 
dent performance and its link to instruction. In Cincinnati, content-based assistance took the form of SIP. In Philadelphia, the district's literacy initiative gave teachers a set of strategies - including guided reading, word study, modeled writing, and shared writing - to employ with their students. Supports include professional development opportunities that afford community members the occasions to improve their instructional craft knowledge, as well as organizational supports that provide both the resources and legitimacy that breaks down obstacles and facilitates the challenging work that communities are being asked to do. If it takes a village to raise our children, then a community of teachers can more effectively instruct them.

\section{About the Authors}

Jonathan A. Supovitz is a Research Assistant Professor at the University of Pennsylvania's Graduate School of Education and a Senior Researcher with the Consortium for Policy Research in Education. He has published findings from a number of educational studies, including several examinations of the relationship between teacher professional development, teaching practice, and student achievement; educational leadership; efforts to develop communities of instructional practice in schools; an examination of the equitability of different forms of student assessment; and the use of technology for evaluative data collection. His current research interests include how districts develop a coherent vision of instructional improvement and support instructional focus in schools, and how today's increasingly complex and systemic reforms influence the definition and distribution of leadership in schools.

Jolley Bruce Christman is Principal of Research for Action and has authored numerous evaluation reports and journal articles including "The Five School Study: Restructuring Philadelphia's Comprehensive High Schools," and "Taking Stock/Making Change: Stories of Collaboration in Local School Reform" (with Fred Erickson). Her research interests include school reform, gender and education, and participatory evalua- tion. She received the Council on Anthropology and Education's (CAE) award for excellence in ethnographic evaluation and currently serves on CAE's board. Christman also teaches at the University of Pennsylvania.

\section{References}

Christman, J. B, Cohen, J., \& MacPherson, P. (1997). Growing smaller: Three tasks of high school restructuring. Philadelphia: Research for Action.

Darling-Hammond, L., \& Sykes, G. (Eds.). (1999). Teaching as the learning profession: Handbook of policy and practice. San Francisco: Jossey-Bass.

Deming, W. E. (1986). Out of the crisis. Knoxville, TN: SPC Press.

Fine, M., \& Somerville, J. (Eds.) (1998). Small schools, big imaginations: A creative look at urban public schools. Chicago: Cross City Campaign for Urban School Reform.

Galbraith, J. R. (1994). Competing with flexible lateral organizations (second edition). Reading, MA: Addison-Wesley.

Hendrie, C. (1996, October 23). Cincinnati eyes top-to-bottom restructuring. Education Week.

Holtzapple, E. (2001). Standards in practice: Year one evaluation. Cincinnati: Cincinnati Public Schools.

McLaughlin, M. W., \& Talbert, J. E. (2001). Professional communities and the work of high school teaching. Chicago: University of Chicago Press.

Mohrman, S. A., Cohen, S. G., \& Mohrman, A. M. (1995). Designing team-based organizations: New forms for knowledge work. San Francisco: Jossey-Bass.

Resnick, L. B., \& Hall, M. W. (1998). Learning organizations for sustainable education reform. Daedalus, 127(4), 89-118.

Senge, P. (1990). The fifth discipline: The art and practice of the learning organization. New York: Doubleday.

Wenger, E. (1998). Communities of practice: Learning, meaning, and identity. Cambridge, England: Cambridge University Press. 


\section{For More Information}

To learn more about the evaluations of Cincinnati and Philadelphia, you can read the following reports available on the CPRE website (www.cpre.org):

\section{Reports on Cincinnati}

Supovitz, J. A. (1998). Team-based schooling in Cincinnati: The first year. Philadelphia: Consortium for Policy Research in Education, University of Pennsylvania.

Supovitz, J. A. (2001). Team-based schooling in Cincinnati: The fourth year. Philadelphia: Consortium for Policy Research in Education, University of Pennsylvania.

Supovitz, J. A., \& Watson, S. (1999). Teambased schooling in Cincinnati: The second year. Philadelphia: Consortium for Policy Research in Education, University of Pennsylvania.

Supovitz, J. A., \& Watson, S. (2000). Teambased schooling in Cincinnati: The third year. Philadelphia: Consortium for Policy Research in Education, University of Pennsylvania.

\section{Reports on Philadelphia}

Christman, J. B. (1998). Guidance for school improvement in a decentralizing system: How much, what kind, and from where? Philadelphia: Consortium for Policy Research in Education, University of Pennsylvania.

Christman, J. B. (2001). Powerful ideas, modest gains: Five years of systemic reform in Philadelphia middle schools. Philadelphia: Consortium for Policy Research in Education, University of Pennsylvania.

Christman, J. B., \& Rhodes, A. (2002). Civic engagement and urban school improvement: Hard-to-learn lessons from Philadelphia. Philadelphia: Consortium for Policy Research in Education, University of Pennsylvania.
Corcoran, T., \& Christman, J. B. (2002). The limits and contradictions of systemic reform: The Philadelphia story. Philadelphia: Consortium for Policy Research in Education, University of Pennsylvania.

Foley, E. (1998). Restructuring student support services: Redefining the role of the school district. Philadelphia: Consortium for Policy Research in Education, University of Pennsylvania.

Foley, E. (2001). Contradictions and control in systemic reform: The ascendancy of the central office in Philadelphia schools. Philadelphia: Consortium for Policy Research in Education, University of Pennsylvania.

Gold, E., Rhodes, A., Brown, S., Lytle, S., \& Waff, D. (2001). Clients, consumers, or collaborators? Parents and their roles in school reform during Children Achieving, 1995-2000. Philadelphia: Consortium for Policy Research in Education, University of Pennsylvania.

Luhm, T., Foley, E., \& Corcoran, T. (1998). The accountability system: Defining responsibility for student achievement. Philadelphia: Consortium for Policy Research in Education, University of Pennsylvania.

Simon, E., Foley, E., \& Passantino, C. (1998). Making sense of standards: Implementation issues and the impact on teaching practice. Philadelphia: Consortium for Policy Research in Education, University of Pennsylvania.

Spiri, M. H. (2001). School leadership and reform: Case studies of Philadelphia principals. Philadelphia: Consortium for Policy Research in Education, University of Pennsylvania.

Watson, S. (2001). Recruiting and retaining teachers: Keys to improving the Philadelphia Public Schools. Philadelphia: Consortium for Policy Research in Education, University of Pennsylvania. 


\section{Recent CPRE Publications}

The following is a list of selected publications reporting on research conducted by the Consortium for Policy Research in Education. Research reports are available for a nominal fee; technical reports and policy briefs are available free-of-charge. For further information, please see below, call (215) 573-0700, ext. 1, or visit us on the world wide web at www.cpre.org

\section{Technical Reports}

The Heart of the Matter: The Coaching Model in America's Choice Schools

Susan Poglinco, Amy Bach, Kate Hovde, Sheila Rosenblum, Marisa Saunders, and Jonathan Supovitz, May 2003 (No charge)

The Impact of Standards-based Reform in Duval County, Florida, 1999-2002

Jonathan Supovitz and Brooke Snyder Taylor, May 2003 (No charge)

Systemic Reform in Practice: Merck Institute for Science Education March 2003 (No charge)

\section{Research Reports}

Changing District Culture and Capacity: The Impact of the Merck Institute for Science Education Partnership Tom Corcoran, November 2003, RR-054 (\$5.00)

The Merck Institute for Science Education: A Successful Intermediary for Educational Reform

Tom Corcoran, March 2003, RR-052 (\$5.00)

Teacher Leadership as a Strategy for Instructional Improvement: The Case of the Merck Institute for Science Education Kate Riordan, March 2003, RR-053 (\$5.00)

\section{Policy Briefs}

Redesigning Accountability Systems for Education

Susan H. Fuhrman, September 2003 (No charge)

What Explains Differences in International Performance? TIMSS Researchers Continue to Look for Answers Deborah I. Nelson, September 2003 (No charge)

Prices include book-rate postage and handling. Make checks payable to Trustees of the University of Pennsylvania. Sorry, we cannot accept returns, credit card orders, or purchase orders. Sales tax is not applicable. To obtain copies, write: CPRE Publications, Graduate School of Education, University of Pennsylvania, 3440 Market Street, Suite 560, Philadelphia, PA 19104-3325

\section{Books}

Books must be ordered directly from the publisher indicated.

All Else Equal: Are Public and Private Schools Different?

Luis Benveniste, Martin Carnoy, and Richard Rothstein, 2003, \$19.95

Available from Routledge: www.routledge.com

California Dreaming: Reforming Mathematics Education

Suzanne Wilson, 2003, \$29.95

Available from Yale University Press: www.yale.edu/yup/books/094329.htm

The New Accountability: High Schools and High-stakes Testing

Martin Carnoy, Richard F. Elmore, and Leslie S. Siskin (Eds.), 2003, \$19.95

Available from Routledge: www.routledge.com

Who Controls Teachers' Work? Power and Accountability in America's Schools

Richard M. Ingersoll, 2003, \$39.95

Available from Harvard University Press: www.hup.harvard.edu/catalog/INGWHO.html 


\section{Nondiscrimination Statement}

The University of Pennsylvania values diversity and seeks talented students, faculty, and staff from diverse backgrounds. The University of Pennsylvania does not discriminate on the basis of race, sex, sexual orientation, religion, color, national or ethnic origin, age, disability, or status as a Vietnam era veteran or disabled veteran in the administration of educational policies, programs, or activities; admissions policies, scholarships, or loan awards; and athletic or University-administered programs or employment. Questions or complaints regarding this policy should be directed to Executive Director, Office of Affirmative Action, 1133 Blockley Hall, Philadelphia, PA 19104-6021 or 215-898-6993 (Voice) or 215-898-7803 (TDD).

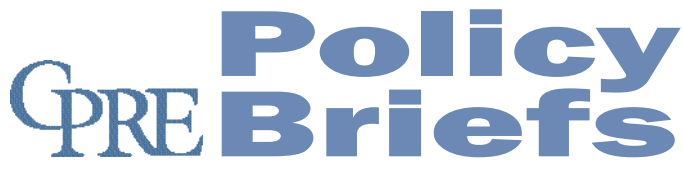

Graduate School of Education

University of Pennsylvania

3440 Market Street, Suite 560

Philadelphia, PA 19104-3325

\section{About CPRE}

The Consortium for Policy Research in Education (CPRE) studies alternative approaches to education reform in order to determine how state and local policies can promote student learning. Currently, CPRE's work is focusing on accountability policies, efforts to build capacity at various levels within the education system, methods of allocating resources and compensating teachers, instructional improvement, finance, and student and teacher standards. The results of this research are shared with policymakers, educators, and other interested individuals and organizations in order to promote improvements in policy design and implementation.

CPRE unites five of the nation's leading research institutions to improve elementary and secondary education through research on policy, finance, school reform, and school governance. Members of CPRE are the University of Pennsylvania, Harvard University, Stanford University, the University of Michigan, and the University of Wisconsin-Madison.

CPRE Policy Briefs are published by CPRE. To learn more about CPRE research or publications, please call 215-573-0700 or access CPRE publications at www.cpre.org; www.wcer.wisc.edu/cpre/; or www.sii.soe.umich.edu.

Philadelphia, PA 19104-3325 